\title{
EXPERIENCE OF MANAGEMENT OF PHYLLODES TUMOR OF BREAST AT A TERTIARY CARE HOSPITAL: A PROSPECTIVE STUDY
}

Bharath $B^{1}$, Lakkanna $S^{2}$, Satyanarayan $V^{3}$, Usharani $R^{4}$, Preetham Raj ${ }^{5}$, Shankarappa $G^{6}$, Arun Kumar S. L7 Sagar $Z^{8}$

1 Junior Resident, Department of General Surgery, ESIC MC PGIMSR, Rajajinagar, Bangalore. 2 Professor and HOD, Department of General Surgery, ESIC MC PGIMSR, Rajajinagar, Bangalore. ${ }^{3}$ Associate Professor, Department of General Surgery, ESIC MC PGIMSR, Rajajinagar, Bangalore. ${ }^{4}$ Assistant Professor, Department of General Surgery, ESIC MC PGIMSR, Rajajinagar, Bangalore. ${ }_{5}^{5}$ Assistant Professor, Department of General Surgery, ESIC MC PGIMSR, Rajajinagar, Bangalore. ${ }^{6}$ Assistant Professor, Department of General Surgery, ESIC MC PGIMSR, Rajajinagar, Bangalore. 7 Junior Resident, Department of General Surgery, ESIC MC PGIMSR, Rajajinagar, Bangalore. 8Junior Resident, Department of General Surgery, ESIC MC PGIMSR, Rajajinagar, Bangalore.

\section{ABSTRACT}

\section{BACKGROUND}

Phyllodes tumors of the breast are a rare fibroepithelial lesions, which is locally aggressive neoplasm. The aim of the study was to report our experience at ESIC MC PGIMSR Hospital (Rajajinagar, Bengaluru) acquired during period of 3 years.

\section{METHODS}

It was a prospective observational study, which included documentation of clinical presentation, pre-operative workup, surgical treatment, complications, histopathological examination and the outcome in a series of 52 cases diagnosed as phyllodes tumor from January 2013 to December 2015.

\section{RESULTS}

The analysis of this series showed that mean time of onset was 12 months [ 6 - 18 months], the chief complaint was lump in the breast in all the patients; tumor size ranged between $4.5-22.5 \mathrm{~cm}$ (mean: $13.5 \mathrm{~cm}$ ); the right breast was affected in 31 cases, surgical treatment was used in all cases which included 44 cases who underwent wide local excision and 8 cases simple mastectomy; the tumor was classified based on histopathological examination as benign in 44 cases (85\%), borderline in 2 cases (4\%) and malignant in 6 cases (11\%); all the patients were followed up, the rate of recurrence was $10 \%$. None of the patient had distant metastasis and no deaths were reported during the study period.

\section{CONCLUSIONS}

Phyllodes tumors of the breast clinically resemble fibroadenoma and have an unpredictable outcome, thus a wide local excision, with an adequate margin of normal breast tissue is the preferred initial therapy.

\section{KEYWORDS}

Phyllodes Tumor, Malignant, Mastectomy, Recurrence.

HOW TO CITE THIS ARTICLE: Bharath B, Lakkanna S, Satyanarayan V, et al. Experience of management of phyllodes tumor of breast at a tertiary care hospital: a prospective study. J. Evolution Med. Dent. Sci. 2016;5(15):707-710, DOI: 10.14260/jemds/2016/163

\section{INTRODUCTION}

Johannes Muller first described a tumor of breast in 1838, which was fleshy and contained cystic spaces with a leaf like architecture, he coined the term cystosarcoma phyllodes which was derived from the Greek word 'phyllodes' meaning leaf like. ${ }^{1}$ The disease was renamed as phyllodes tumour by World Health Organisation (WHO). ${ }^{2}$ Its malignant potential was first described by Cooper and Ackerman in 1943. It is classified under heterogeneous group of fibroepithelial tumours.

Histologically, it is classified as benign, borderline or malignant. The median age of occurrence of disease is 40-50 years. Rarity of the disease, difficulty in pre-operative diagnosis and its tendency to recur and poor response to chemotherapy and radiotherapy leads to delay in diagnosis.

Financial or Other, Competing Interest: None.

Submission10-01-2016, Peer Review 04-02-2016,

Acceptance 10-02-2016, Published 22-02-2016.

Corresponding Author:

Dr. Bharath $B$,

MF 21/4, U Block, Near SBM Officers Quarters,

Nandini Layout,

Bangalore-560096.

E-mail: bharathbasavraj@gmail.com

DOI: $10.14260 /$ jemds $/ 2016 / 163$
The aim of the study is to evaluate the clinical data, pathology, treatment and outcome of the disease.

\section{MATERIALS AND METHODS}

It is a prospective observational study for a period of 3 years from January 2013 to December 2015 including the follow-up period of 6 months. The data collected included demographic, presenting complaint, size of the tumor and its localization, FNAC, ultrasonography, preoperative diagnosis, surgical procedure, pathological findings and outcome. Grading into benign, borderline and malignant was performed preoperatively based on FNAC findings and patients were subjected to wide local excision for benign cases and simple mastectomy for malignant cases and were postoperatively followed up for recurrence. One patient was subjected to radiotherapy; none of the patients were subjected to chemotherapy.

\section{RESULTS}

Fifty two patients with histologically proven cystosarcoma phyllodes of the breast were diagnosed. Forty one cases were diagnosed to have phyllodes tumor by FNAC before surgery, which accounted to $78.2 \%$. Mean age at diagnosis was 37.7 $(37.7+/-23.5)$ years, median also was 38 years. 
The youngest and eldest patients were 14 and 61 years old at diagnosis, respectively. Five patients showed a history of previous fibroadenoma, but none had been diagnosed with breast cancer; 31 patients (59.61\%) of the tumours occurred in the right; $21(40.39 \%)$ in the left breast. Tumor occupied all quadrants in $46 \%$ of patients; $37 \%$ patients had tumour in upper outer quadrant and lower outer quadrant in $12 \%$.

No case of bilateral phyllodes tumor was recorded. The tumors were classified histologically into benign (85\%), borderline (4\%) and malignant tumours (11\%) based on 2003 World Health Organization (WHO) classification taking into account stromal cellularity and overgrowth, cellular atypia mitotic activity and microscopic tumor borders. ${ }^{3}$ Breast conserving procedure was done in 44 cases (85\%) and simple mastectomy in 8 cases (15\%), one of the patients was treated with adjuvant radiotherapy after primary surgery due to chest wall invasion. Mean tumour size was $13.5+/-9.0 \mathrm{~cm}$. The smallest tumour was $4.5 \mathrm{~cm}$ in size and the largest was a very large phyllodes tumour of $22.5 \mathrm{~cm}$ diameter.

A $56 \%$ of the (29 of 52 ) patients had a tumour of less than $5 \mathrm{~cm}$ diameter; $17 \%(9 / 52)$ had a tumour between 5 and $10 \mathrm{~cm}$ and $27 \%(14 / 52)$ had tumours of more than $10 \mathrm{~cm}$ diameter. Surgical removal of lymph nodes was performed in 2 cases due to presence clinical palpable lymph nodes with prior diagnosis of malignant phyllodes tumor. No lymph node infiltration was found in any of the patients who underwent axillary lymph node dissection.

Local recurrence occurred in 5 of 52 patients (10\%). All of them with a local recurrence had been treated with breast conserving surgery [Wide local excision]. Distant metastases were not seen in any patients, ruled out by chest X-ray and Xray of long bones and skull.

\section{Patient and Tumour Related Characteristics}

\begin{tabular}{|c|c|}
\hline Total number of patients & $\mathbf{5 2}$ \\
\hline Age (Range) & 14-61 years \\
\hline Mean age & 38 years \\
\hline Localisation of tumour & R-31, L-21 \\
\hline Histology & 44 \\
\hline Benign phyllodes & 2 \\
\hline Borderline phyllodes & 6 \\
\hline Malignant phyllodes & \\
\hline Size & 29 \\
\hline$<5$ cm & 9 \\
\hline $5-10$ cm & 14 \\
\hline$>10$ cm & 44 \\
\hline Surgery & 8 \\
\hline Conservative surgery & 2 \\
\hline Mastectomy & 1 \\
\hline Axillary dissection & 5 \\
\hline Radiotherapy & 0 \\
\hline Local recurrence & \\
\hline Distant Metastasis & \\
\hline
\end{tabular}

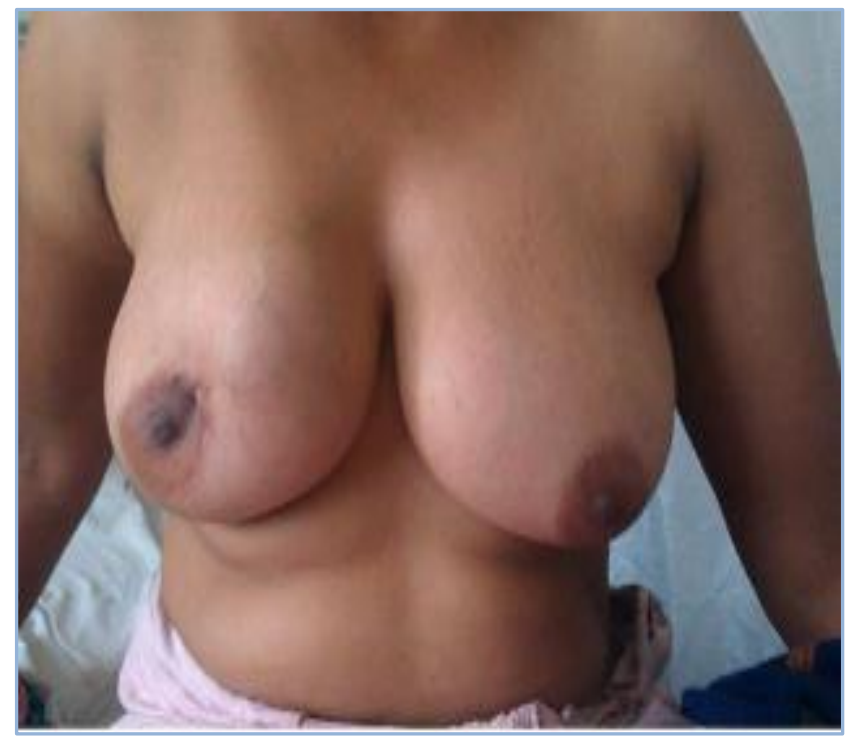

Fig. 1: Clinical Photograph of Malignant Phyllodes Tumor of Right Breast

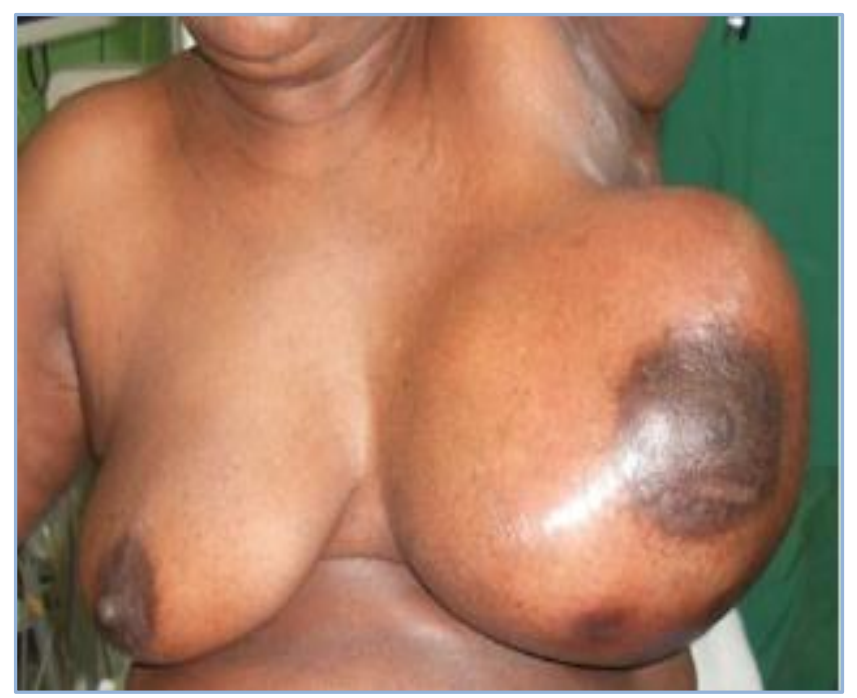

Fig. 2: Clinical Photograph of Malignant Phyllodes Tumor of Left Breast

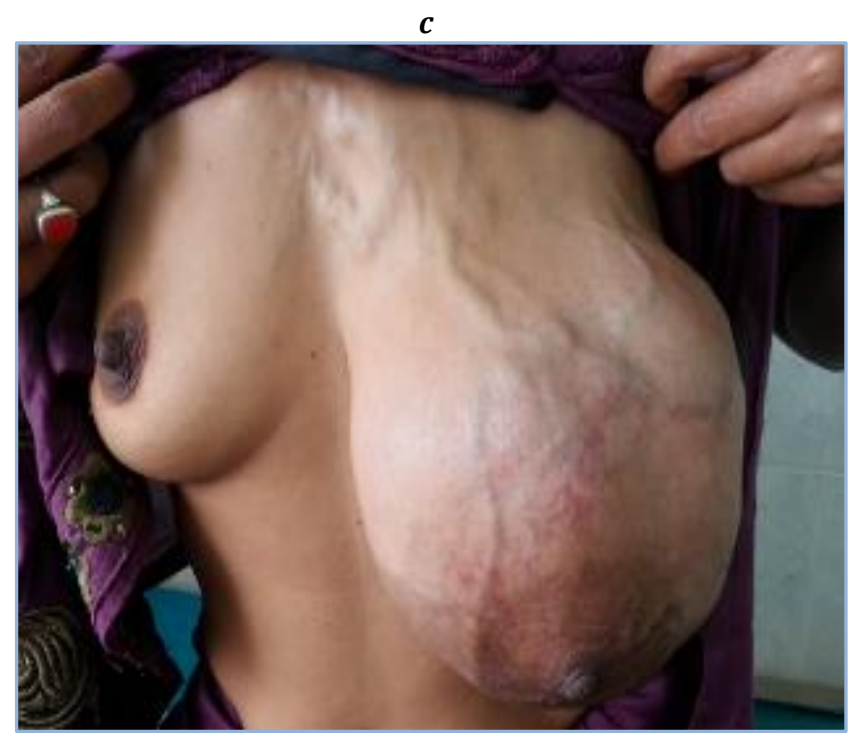

Fig. 3: Clinical Photograph of Malignant Phyllodes Tumor of Left Breast 


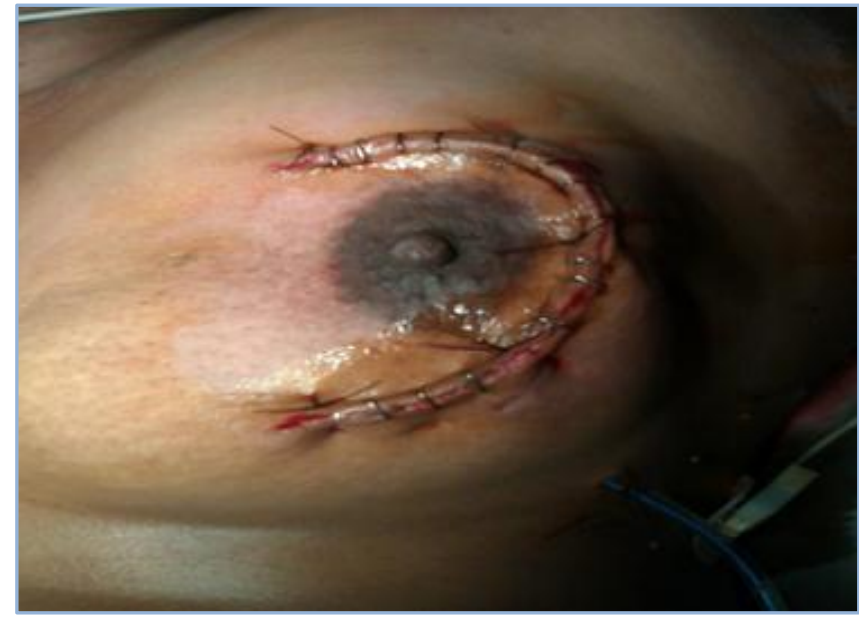

Fig. 4: Post Wide Local Excision

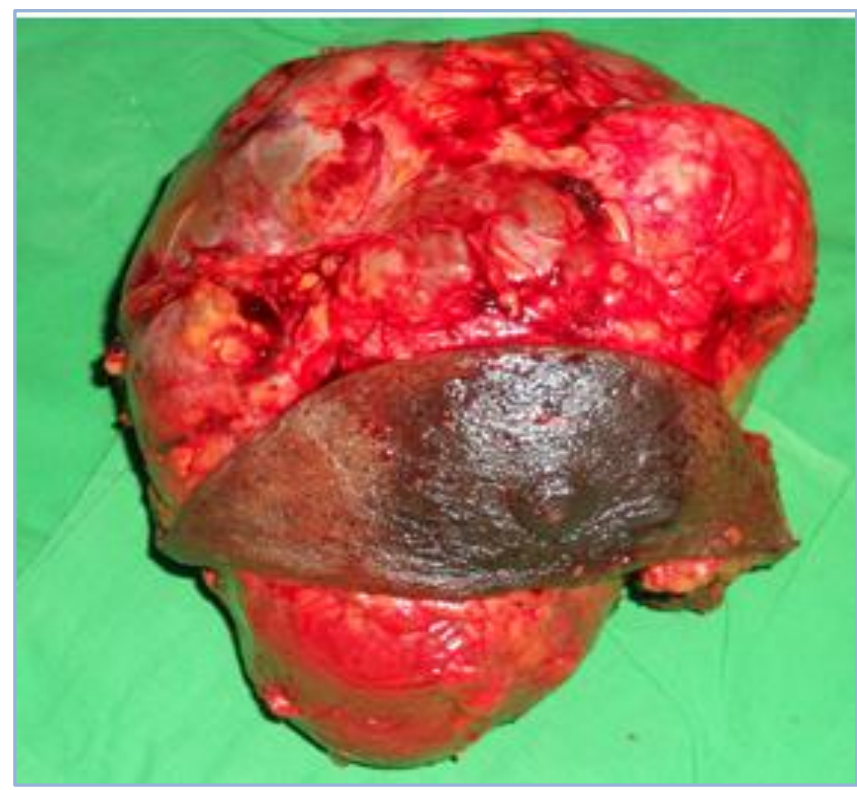

Fig. 5: Resected Specimen of Breast - Simple Mastectomy of Left Breast

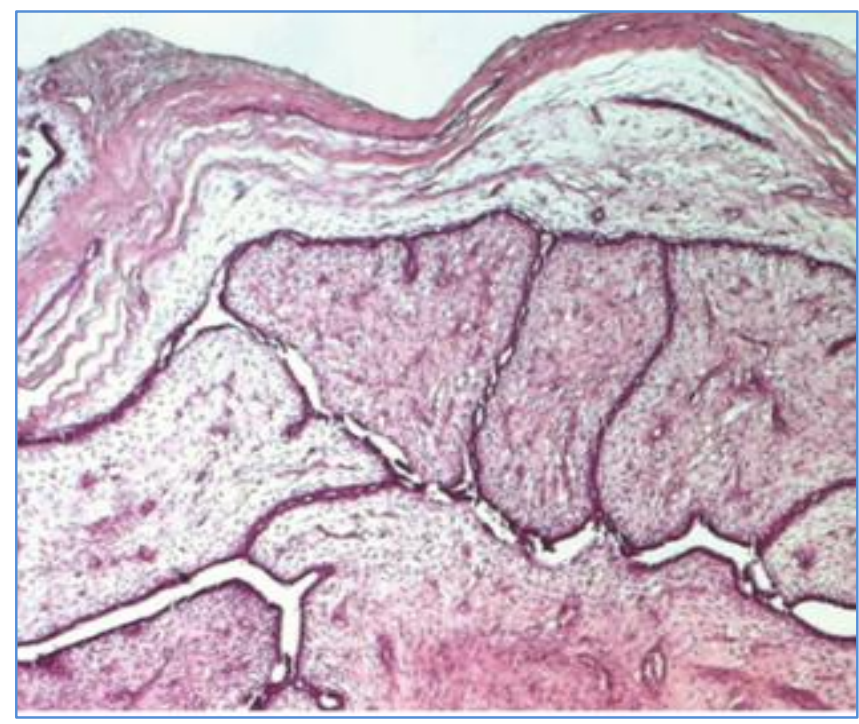

Fig. 6: Benign: containing leaf-like, epithelial-lined papillary projections penetrating into cystic spaces

\section{DISCUSSION}

Phyllodes tumors of breast are rare tumors comprising of both stromal and epithelial elements. ${ }^{4}$ They occur in $4^{\text {th }}$ to $5^{\text {th }}$ decade of life. Clinically, they are painless lumps with rapid growth in size resembling fibroadenoma. Multi-focality has been reported in literature where the highest incidence of up to $12 \%$ was reported by Ben Hassouna. ${ }^{5}$ whereas bilateral cases are rare being from 0 to $3.5 \%{ }^{6}$ In our series we did not encounter multi-focality or bilateral cases. Histopathologically it exists in benign, borderline and malignant subtypes, although there is no unanimous agreement on the criteria in assigning subtype and in prediction of the biological behaviour.7 $^{7}$

The risk of local recurrence is irrespective of histology, although the events are more frequent in the malignant and borderline tumors than in benign group. Among the benign and borderline tumors all local relapses can be well managed by further surgery (Either breast-conserving surgery or mastectomy). In this group (Benign/borderline) positive surgical margins do not seem to predict a worse outcome. Diagnosis of phyllodes tumor on ultrasound and mammography and FNAC are in adequate to reliably distinguish phyllodes tumor from fibroadenoma. 7 in the present study, malignant tumors accounted for $12 \%$ of the phyllodes tumors. The share of malignant phyllodes tumors described in literature varies from 8 to $45 \%{ }^{8}$

Surgical treatment is generally the primary treatment of choice for phyllodes tumor, regardless of its histological subtype. ${ }^{9}$ most studies recommend minimum of 10 to $20 \mathrm{~mm}$ tumor free margin.10,11,12 but due to a large size of the tumor, excision with required margin is impossible due to presence of narrow breast tissue surrounding the tumor. Lumpectomy or partial mastectomy is the preferred surgery of choice, total mastectomy is necessary only if negative margins cannot be obtained. ${ }^{13}$

Since phyllodes tumor rarely metastasizes to axillary lymph node, axillary lymph node metastases are described in less than $10 \%$ of malignant phyllodes tumors. ${ }^{10}$ Surgical axillary clearance or dissection is unnecessary unless lymph nodes are pathologic on clinical examination. Metastatic spread occur mostly haematogenous and the organs most commonly affected by metastatic spread are the lungs, pleura and bones. ${ }^{11}$ we did not have any patient with distant metastasis.

The incidence of local recurrence varies, probably mainly due to the small number of patients, between 9 and 29\%. ${ }^{10}$ In our study recurrence was seen in 5 patients and accounted to $10 \%$, neither radiotherapy nor chemotherapy play a dominant role for adjuvant therapy.14 Radiotherapy has been used with good results for local control of the disease. 15

\section{CONCLUSION}

Phyllodes tumors of the breast clinically resemble fibroadenoma and have similar features and it is difficult to diagnose by FNAC as the sensitivity is variable and utilisation of mammography and ultrasound appearances are nonspecific. Frozen section is useful to know the status of the margin intra-operatively as the disease is known for high recurrence. Local excision with appropriate surgical margins seems adequate in all patients; patients with a malignant tumour are at higher risk for local recurrence and metastatic 


\section{Jemds.com}

spread and the histopathological examination seems to be most important prognostic factor.

\section{REFERENCES}

1. Müller J. Über den feineren Bau und Die Formen der Krankaften Geschwulste, vol. 1. Berlin: Greiner; 1838, PP. 54-7.

2. The World Health Organisation. Histological typing of breast tumors - Second Edition. The World Organisation. Am J Clin Pathol 1982;78(6):806-16.

3. Bellocq JP, Magro G. Fibroepithelial tumors. In: Tavassoli FA, Devilee P, eds. World Health Organization Classification of Tumors: Tumors of the Breast and Female Genital Organs. Lyon, France: IARC Press; 2003;99-103.

4. Telli ML, Horst KC, Guardino AE, et al. Phyllodes tumors of the breast: natural history, diagnosis and treatment. J Natl Compr Canc Netw 2007;5:324-330.

5. Ben Hassouna J, Damak T, Gamoudi A, et al. Phyllodes tumors of the breast: a case series of 106 patients. American Journal of Surgery 2006;192(2):141-7.

6. Barrio AV, Clark BD, Goldberg JI, et al. Clinicopathologic features and long-term outcomes of 293 phyllodes tumors of the breast. Annals of Surgical Oncology 2007;14(10):2961-70.

7. Anderson BO, Lawton TJ, Lehman CD, et al. Diseases of the breast, third edition. Philadelphia: Lippincott Williams \& Wilkins; 2004. pp. 991-1006.

\section{Original Article}

8. Mangi AA, Smith BL, Gadd MA, et al. Surgical management of phyllodes tumors. Arch Surg 1999; 134(5):487-92.

9. Salvadori B, Cusumano F, Del Bo R, et al. Surgical treatment of phyllodes tumors of the breast. Cancer 1989;63:2532-2536.

10. Reinfuss M, Mitus J, Duda K, et al. The treatment and prognosis of patients with phyllodes tumor of the breast: an analysis of 170 cases. Cancer 1996;77(5):910-6.

11. Kapiris I, Nasiri N, A'Hern R, et al. Outcome and predictive factors of local recurrence and distant metastases following primary surgical treatment of highgrade malignant phyllodes tumours of the breast. Eur J Surg Oncol 2001;27(8):723-30.

12. Pandy M, Matthew A, Jayabreek I. Malignant phyllodes tumor. Breast Journal 2001;71:411-6.

13. Chaney AW, Pollack A, McNeese MD, et al. Primary treatment of cystosarcoma phyllodes of the breast. Cancer 2000;89:1502-1511.

14. Sheen-Chen SM, Chou FF, Chen WJ. Cystosarcoma phylloides of the breast: a review of clinical, pathological and therapeutic option in 18 cases. Int Surg 1991;76(2):101-4.

15. Stockdale AD, Leader M. Phyllodes tumour of the breast: response to radiotherapy. Clin Radiol 1987;38(3):287. 